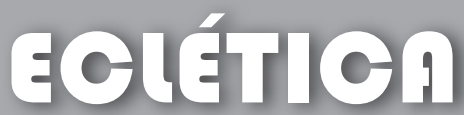 química
}

\section{MONITORAMENTO DO CORANTE PARAROSANILINA EM AMOSTRAS BIOLÓGICAS}

\author{
Humberto da Silva Junior; Gutto Raffyson Silva de Freitas; Diogo Roberto Ferreira Néri; Francisco Régis \\ da Silva Pereira; Robson Fernandes de Farias; Francisco Claudece Pereira*
}

Departamento de Química - Universidade Federal do Rio Grande do Norte UFRN, Brasil

C P 1524, 59072-970, Natal-RN, Brasil.

*E-mail: claudece@ufrnet.br

\begin{abstract}
Resumo: O corante pararosanilina (P) é um pigmento que apresenta um relevante papel na análise de substâncias química e bactérias do tipo Gram positivo e negativo, além de outros microorganismos. Os ensaios potenciométricos de $\mathrm{P}$ mostraram que o corante é um ácido monoprótico e fraco $(\mathrm{pKa}=8,78)$; enquanto a espectrofotometria permitiu estimar seu coeficiente de absortividade molar $(\varepsilon)$ igual a $1,48 \times 10^{4} \mathrm{~mol}^{-1} \mathrm{~cm}^{-1} \mathrm{~L}$. A curva analítica para a determinação de $\mathrm{P}$ apresenta linearidade entre $7,36 \times 10^{-6}$ a $7,36 \times 10^{-5} \mathrm{~mol} \mathrm{~L}^{-1}$ e a metodologia foi aplicação em amostras biológicas.
\end{abstract}

Palavras-chave: pararosanilina, constante de ionização, coeficiente de absortividade molar, determinação.

\section{Introdução}

A conhecida classe dos corantes, baseada na família dos trifenilmetanos, é largamente utilizada na indústria têxtil na pigmentação de nylon, lã, algodão, seda, etc. De forma similar, estes pigmentos desenvolvem um papel relevante quando usados em ensaios bacteriológicos e histopatológicos, bem como na identificação de patógenos de interesse da clínica médica, enquanto outros apresentam ampla atividade bactericida e fungicida [1].

De acordo com a literatura [2] esta categoria de corantes pode apresentar riscos quanto a neoplasia de tecidos, devido intoxicações por atividades ocupacionais e/ou contaminação ambiental. A toxicidade destes, baseia-se em sua reatividade com espécies oxigenadas ou excitação durante terapias fotodinâmicas. Assim, seu potencial carcinogênico encontra-se correlacionado a sua oxidação através de sistemas específicos, ou pela ação da enzima peroxidase, produzida pela tireóide, gerando aminas primárias e aromáticas [3].

Pararosanilina $(\mathrm{P})$, cloridrato de benzenoamina 4-(4-aminofenil)(4-imino-2,5-ciclohexadiano-1-ilideno)-metil, paramagenta, magenta ou fucsina básica (CAS 569-61-9; CI 42500), Figura 1, é um corante da família dos triarilmetanos, e tem destacada aplicação da análise de diversos compostos nas mais distintas matrizes, além de apresentar potencialidades na investigação clínica de bactérias do tipo Gram positivo e negativo e outros tipos de microorganismos [2]. 


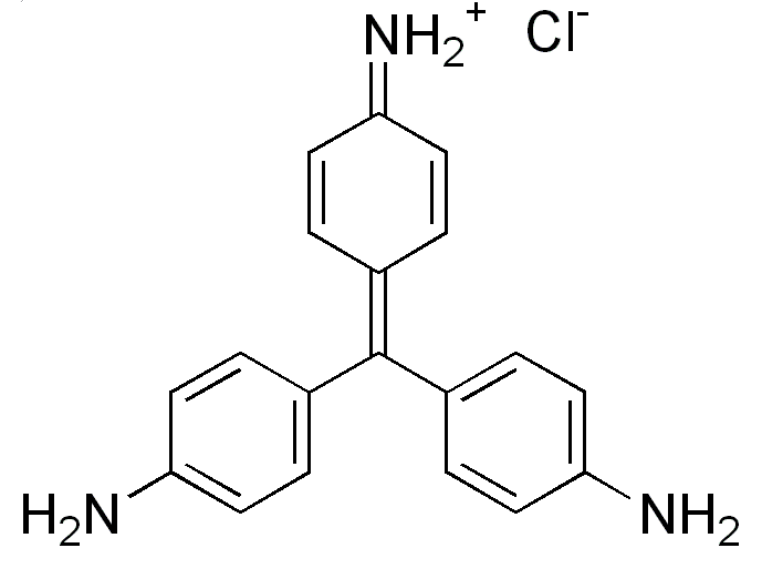

Figura 1. Fórmula estrutural da pararosanilina.

Este composto é um dos raros corantes que apresenta a propriedade de se tornar inflamável em determinadas condições. Além de amplamente utilizado pela indústria têxtil e de curtume, também apresenta larga atividade como marcador de colágeno, tecido muscular e mitocondrial, além de identificador da presença do bacilo de Koch. Em adição, o corante possui amplo espectro anestésico, bactericida e fungicida. Suas propriedades toxicológicas manifestam-se pla initação da derme, dos olhos, apalho respiratorio; podendo arme, dos olhos, apretho respiratónio; podendo alcançar o trato gastrointestinal provocando náuseas, vônitos, diarréia etc. Relatos da lituratura têm mostrado que a exposição prolongada ao corante, pode causar danos aos constituintes do sangue, figado, baço e na tireóide, bem como ao sistema nervoso, além de sintomas de enxaqueca, vertigens, letargias e contração muscular [4]. Alguns trabalhos têm mostrado que o corante encontra-se associado ao aumento no risco de incidência de câncer de bexiga [5].

Muitos dos impactos ambientais, decorrentes de descartes sem prévio tratamento de águas contendo esta categoria de corantes, são atribuídos a interações químicas do tipo não covalentes com componentes celulares, tais como, ácidos nucleicos e membranas; alem de eventos redox irreversíveis gerando radicais livres [6].

Comumente, as águas de descartes, impregnadas com este tipo de corante, são tratadas através do emprego de métodos que incluem adsorção, precipitação, floculação, fotólise, oxidação e

redução, tratamento eletroquímico e extração por formação de par iônico [1].

Assim, e considerando o alto risco de descarte deliberado deste tipo de corante em corpos d’água, sistemas aqǘferos e mananciais de abasdégua, sistená aq âs-

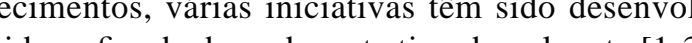
7-14]

Do ponto de vista da análise química, o corante P tem encontrado larga aplicação na determinação das mais variadas espécies. O monitoramento espectrofotométrico de $\mathrm{SO}_{2}$ pode ser al-

cançado através de sua conversão a um cromóforo produzido com o corante [15-20]. De forma similar, a aplicação de protocolos experimentais apropriados, capata álise de distintos conpostos, pris cos, cacacita a ácilise de distintos compostos, ena . [23, 24], brometo [25], $\mathrm{SO}_{3}^{-2}[26,27]$, Formaldeido [28-35], $\mathrm{H}_{2} \mathrm{~S}$ [36-38], o pesticida organoclorado endosulfano [39], substancias tensoativas [40], os metais ouro [41] e Paládio [42].

Dados da literatura mostram que o corante pode ser determinado diretamente através de técnicas espectrofotométricas. O protocolo experimental relata 0 emprego de nanopartículas de óxido de ferto $\left(\mathrm{Fe}_{3} \mathrm{O}\right)$ en de Oxill de forlo a fim de possibilitar a adsor Pno se sódio, a fin de possibilitar a adsorção de cha superficie das na de possibilis a a âmeno capacita as nanoparticulas de ferro a uma etapa de pré-concentração e separação deste analito de uma dada matriz. O emprego de técnicas de absorção molecular na região ultravioleta e visível permitiu estabelecer uma curva de trabalho para $\mathrm{P}$ que apresenta linearidade no intervalo de concentração entre 10 a $300 \mathrm{ng} \mathrm{mL}^{-1}$ e limite de detecção de $7,3 \mathrm{ng} \mathrm{mL}^{-1}$ e desvio-padrão de $4 \%$. A sistemáproposta foi aplicada na analise de amostras um dos rios existentes no Irã [43]

A finalidade do presente trabalho é investigar o comportamento potenciométrico e espec rofotométrico do corante pararosanilina em meio aquoso, em amplo intervalo de $\mathrm{pH}$. Estabelecer as melhores condições experimentais para a sua determinação em matrizes biológica, e extrair alguns parâmetros químicos, tais como sua constante de ionização (Ka) e seu coeficiente de absortividade molar $(\varepsilon)$. pelo Centro de Formação Tecnológico (CEFET)

\section{Equipamentos}

Um espectrofotômetro UV-VIS 1650 PC d marca Shimadzu. Todos os experimentos foran conduzidos com cubetas de quartzo de $1 \mathrm{~cm}$ de caminho ótico. Para a preparação de todas as soluções de trabalho foi empregada uma balança analítica da marca Marte Mict. Todos os valores de $\mathrm{pH}$ das soluções utilizadas foram ajustados com um pHmetro da marca Marconi PA200, modelo RS232. Antes de seu uso, o eletrodo combinando de vidro foi previamente calibrado com as solucões fornecidas pelo fabricante. Este equipamento çám foi empregado para os estudos volumétricos do corante.

\section{Reagentes}

Corante pararosanilina (Merck), ácido acético (Vtec), ácido fosfórico (Merck), ácido bórico (Merck), hidróxido de sódio (Merck), biftalato de potássio (Merck) e etanol (Merck). Todos os reagentes apresentavam grau analítico.

\section{Procedimentos experimentais}

Soluções tampão Britton e Robinson (BR) foram obtidas através da mistura dos ácidos acético, fosfórico e bórico. $\mathrm{O}$ pH das soluções, no intervalo de 2 a 12, foi ajustado pela adição de hidróxido de sódio. Soluções do corante foram obtidas através da dissolução do sal diretamente em água. Todas as soluções foram montadas utilizando água destilada.

A curva volumétrica de $P$ foi gerada através da adição de $40 \mathrm{~mL}$ de $P$ na concentração de $0,0948 \mathrm{~mol} \mathrm{~L}^{-1}\left(50 \% \mathrm{H}_{2} \mathrm{O}: \mathrm{C}_{2} \mathrm{H}_{6} \mathrm{O}\right)$ em um becke e, na bureta, $\mathrm{NaOH} 0,0936 \mathrm{~mol} \mathrm{~L}^{-1}$, previamente padronizado.

As amostras aquosas, contendo materia biológico e o corante $\mathrm{P}$, foram gentilmente cedidas da cidade de Natal-RN. Estas foram coletas e, antes da análise, submetidas a processos de diluição.

\section{Resultados e discussã}

\section{Comportamento potenciométrico de}

O estudo preliminar sobre o comportamento do corante $\mathrm{P}$, em função das variações nos valores de $\mathrm{pH}$ do meio reacional, foi avaliado através da construção da curva volumétrica (pH versus volume de $\mathrm{NaOH}$ ). O resultado deste ensaio é mostrado na Figura 2. 


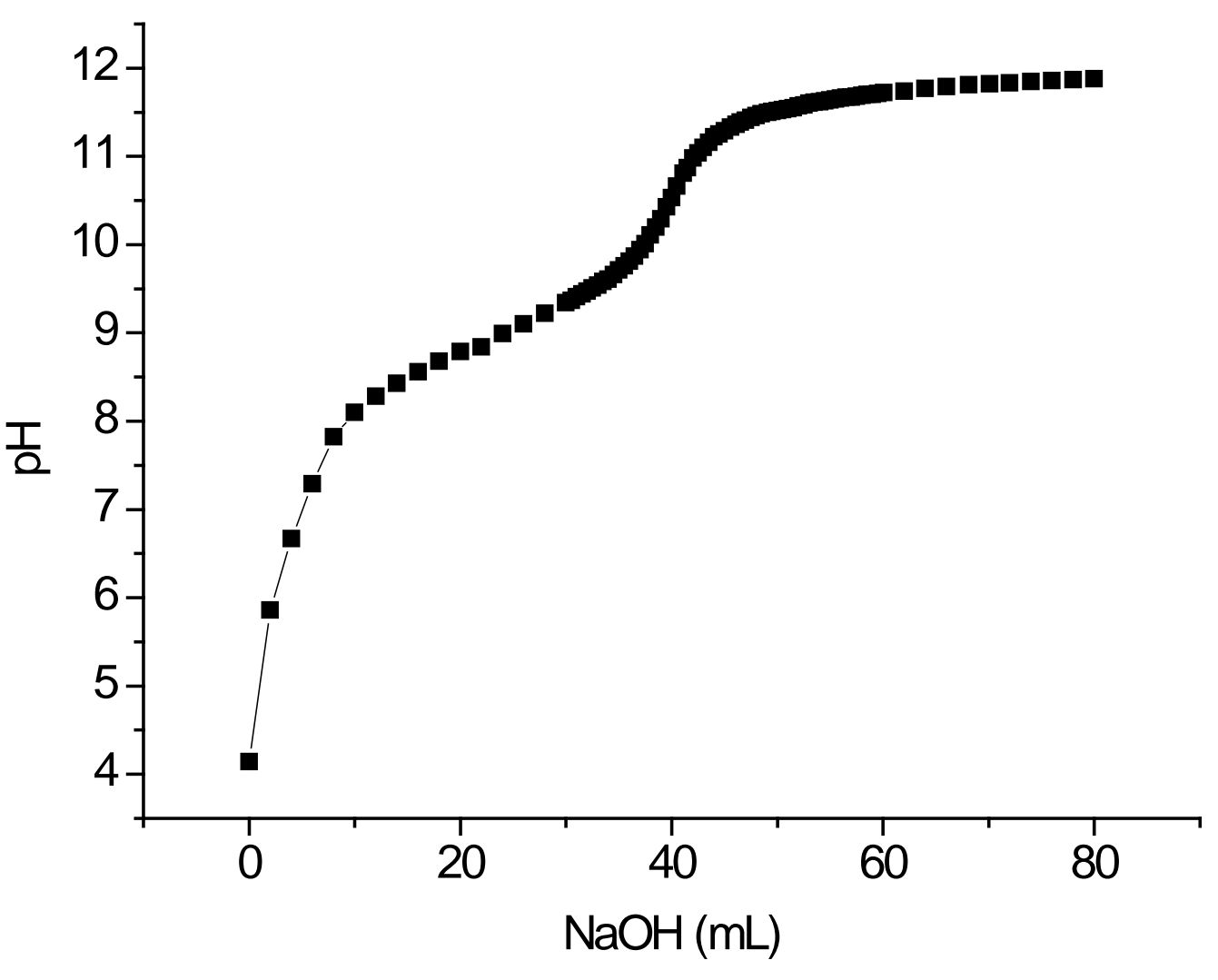

Figura 2. Curva volumétrica da titulação de $40 \mathrm{~mL}$ de $\mathrm{P} 0,095 \mathrm{~mol} \mathrm{~L}^{-1}$ com $\mathrm{NaOH} 0,094 \mathrm{~mol} \mathrm{~L}^{-1}$.

A curva sigmoidal mostra que o corante se comporta como um ácido fraco [44]. Somente um ponto de equivalência pode ser constatado em valores de 40,5 mL da adição de $\mathrm{NaOH}$, confirmando que a substância é um ácido monoprótico. Estes resultados são condizentes com o processo de desprotonação de um dos grupos aminas existentes na estrutura do corante, (Figura 1).

Os dados volumétricos permitiram calcular as concentrações da espécie salina e do ácido remanescente. Soluções que apresentam este tipo de componentes s̃̃o chamadas de soluços reguladoras e, seus estudos são regidos pela relão de Henderson que permite a avaliação [e $\mathrm{pH}$ deste $\mathrm{pH}=\mathrm{pKa}+\log \{[$ [sal $] /$ [ácido $\}$.
No caso da titulação de corante pararosanilina com $\mathrm{NaOH}$ a função salina será representada por P, enquanto sua forma ácida por HP. Assim, e considerando esta relação como uma função linear, o gráfico dos valores das concentrações de P e HP em função do $\mathrm{pH}$ permite determinar o valor de pKa. Esta relação é mostrada na Figura 3.

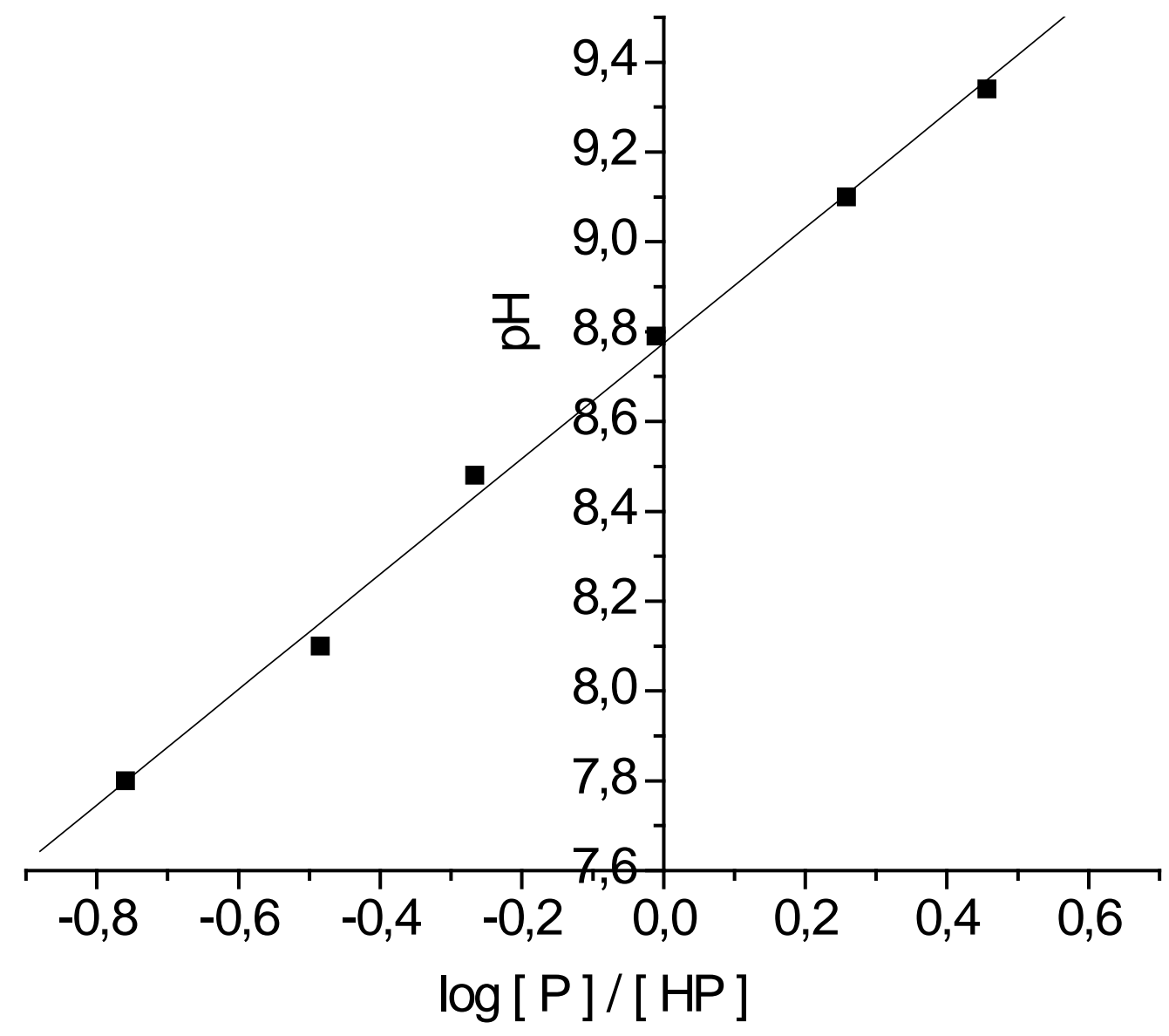

Figura 3. Gráfico da relação de pH versus log $\{[\mathrm{P}]$ / [ HP ] $\}$

A regressão linear destes dados permite a obtenção do coeficiente linear igual a 8,78. Este valor fornece o pKa da forma ácida (HP) o que

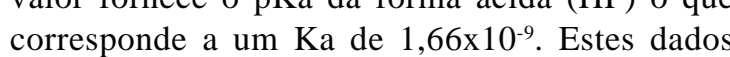
mostram que o ácido apresenta uma pequena constante de ionização e, portanto, é uma substância fraca.

Comportamento espectrofotométrico de $P$

ectrofotométrico de foi inicialmente investigado para concentração de 6,0x10-5 $\mathrm{mol} \mathrm{L}^{-1}$ em solução tampão B-R pH 3,0. Os espectros são bem caracterizados apresentando duas bandas de absorção. Em $\lambda 545 \mathrm{~nm}$ observa-se um intenso pico correspondente a absorção d estrutura quinoidal existente no corante [7]. Em $\lambda$ $289 \mathrm{~nm}$ é possível constatar a ocorrência de um pequeno evento atribuído a absorção da radiação eletromagnética pelas funções aromáticas do pigmento. Em $\lambda 490 \mathrm{~nm}$ e $\lambda 340 \mathrm{~nm}$ registram-se pequenos ombros, Figura 4. 


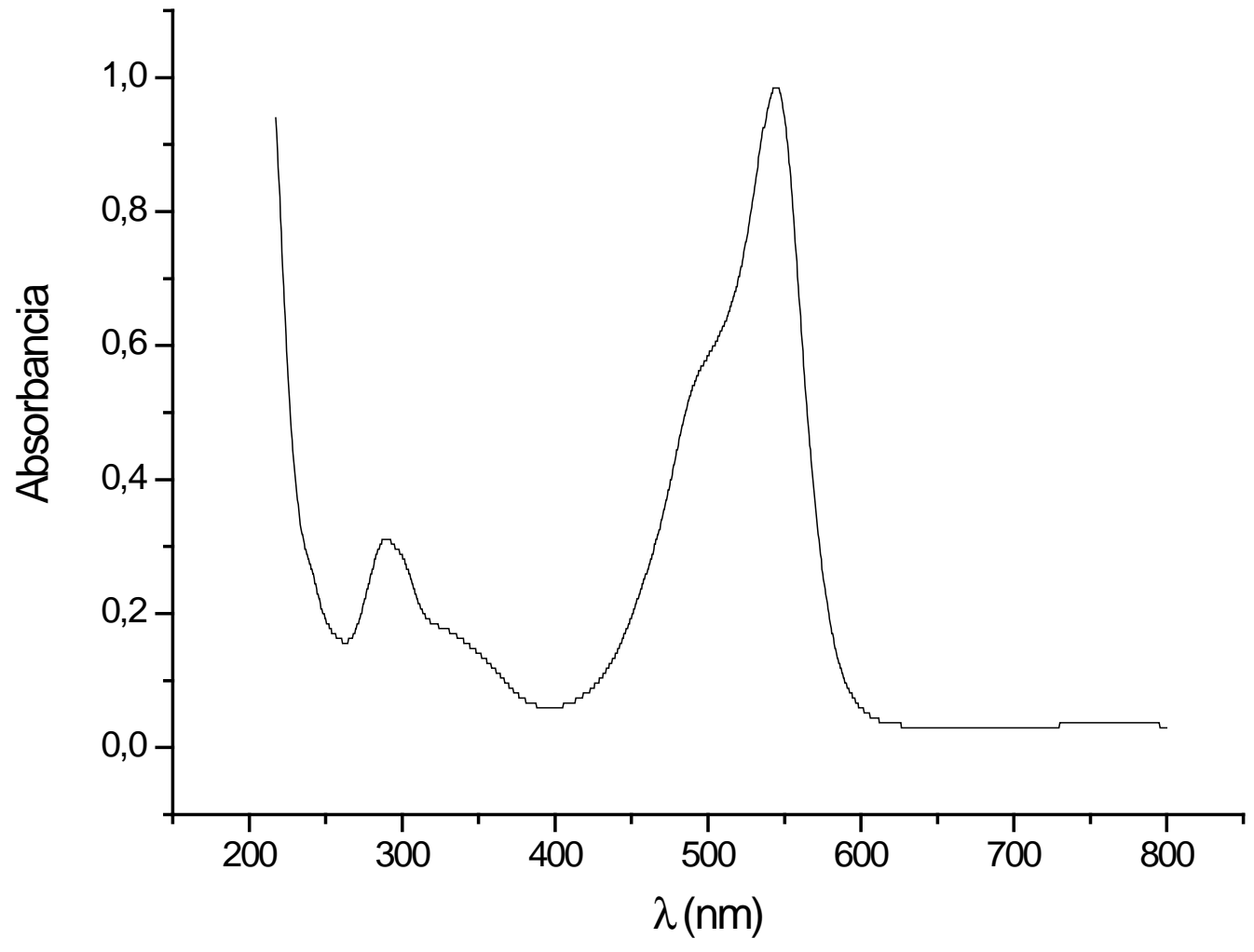

Figura 4. Espectro de absorção de 6,0x10 $0^{-5} \mathrm{~mol} \mathrm{~L}^{-1}$ de pararosanilina em tampão B-R pH 3,0.

O efeito das variações da concentração hidrogeniônica sobre os sinais espectrofotométricos de $8,8 \times 10^{-5} \mathrm{~mol} \mathrm{~L}^{-1}$ de $\mathrm{P}$ foi avaliado em amplo intervalo de $\mathrm{pH}$ de 2,0 a 12,0 em sistema tamponante B-R, Figura 5
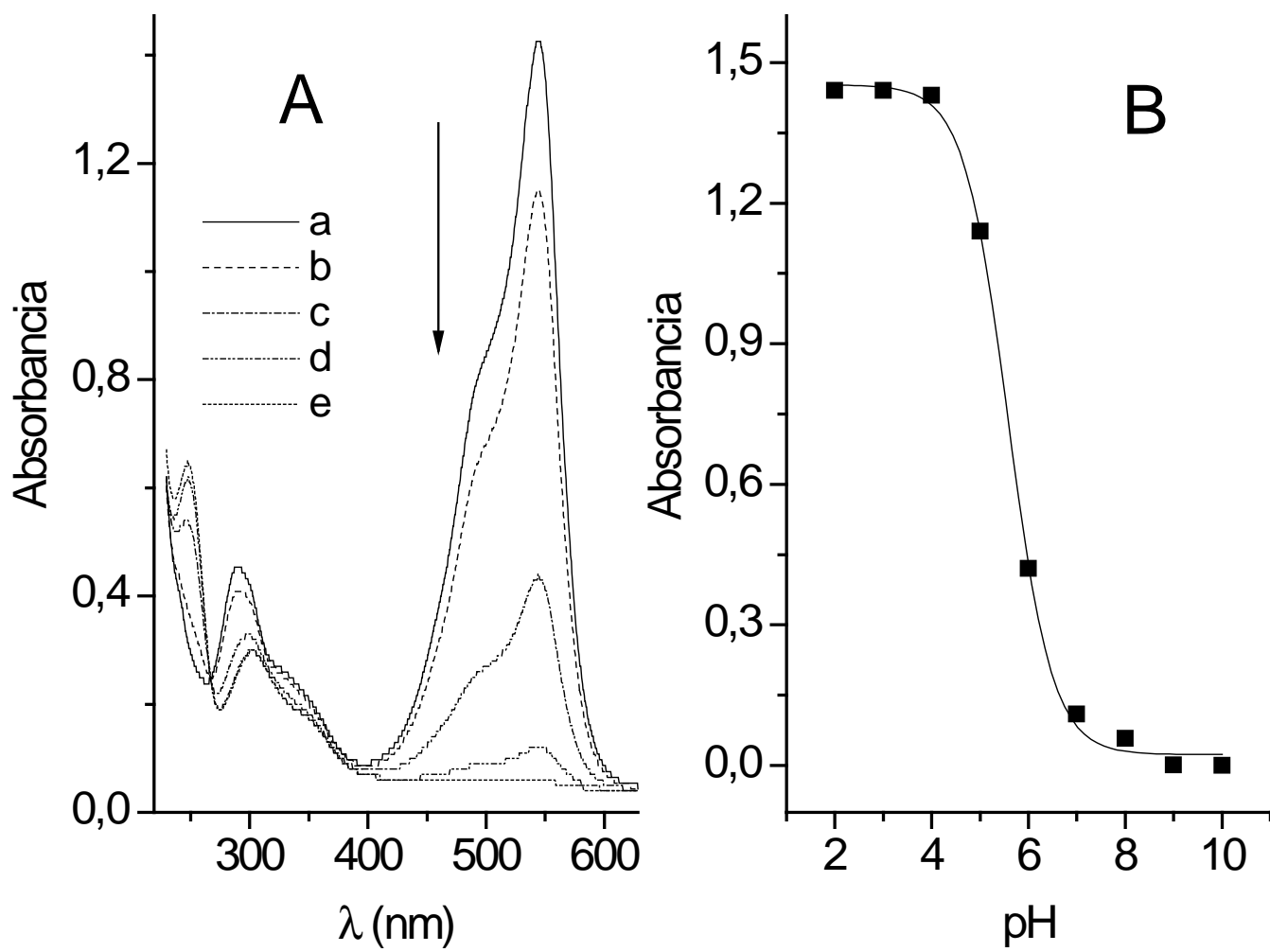

Figura 5 (A). Espectros de absorção molecular (UV-Vis) para 8,8x10 $\mathrm{mol} \mathrm{L}^{-1}$ de $\mathrm{P}$ em função do $\mathrm{pH}$. Curvas: (a)= pH 4,0; (b)= pH 5,0; (c)= pH 6,0; (d)= pH 7,0 e (e)= pH 8,0. (B): Efeito do $\mathrm{pH}$ sobre os sinais de $\mathrm{P}$.

A banda de absorção na região visível apresenta susceptibilidade em função da variação de pH (Figura 5A). O sinal decresce em função do aumento nos valores de $\mathrm{pH}$ e extingue-se em $\mathrm{pH} \geq$ 8,0. A curva de decaimento do pico em $\lambda 545 \mathrm{~nm}$ mostra um perfil sigmoidal (Figura 5B), enquanto o sinal em $\lambda 289 \mathrm{~nm}$ exibe a mesma relação observada para 0 pico em $\lambda 545 \mathrm{~nm}$; todavia, 0

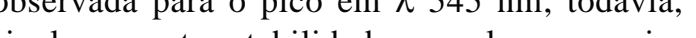
$\mathrm{pH}$. Em adica 0 , o aumento nos valores de de pH. Em ação, o am permite a geração da forma isomérica de $\mathrm{P}$, a qua e possivel ser observada em $\lambda 247 \mathrm{~nm}$ [7]. Como melhor condição de trabalho foi escolhido tampão B-R pH 2,0.

O efeito da concentração de P sobre o sinal de absorbância foi investigado em amplo intervalo de concentração entre $7,36 \times 10^{-6} \mathrm{~mol} \mathrm{~L}^{-1}$
$7,36 \times 10^{-5} \mathrm{~mol} \mathrm{~L}^{-1}$. Os resultados deste ensaio são mostrados na Figura 6 . 
Tabela 1. Concentração do corante pararosanilina em amostras biológicas.

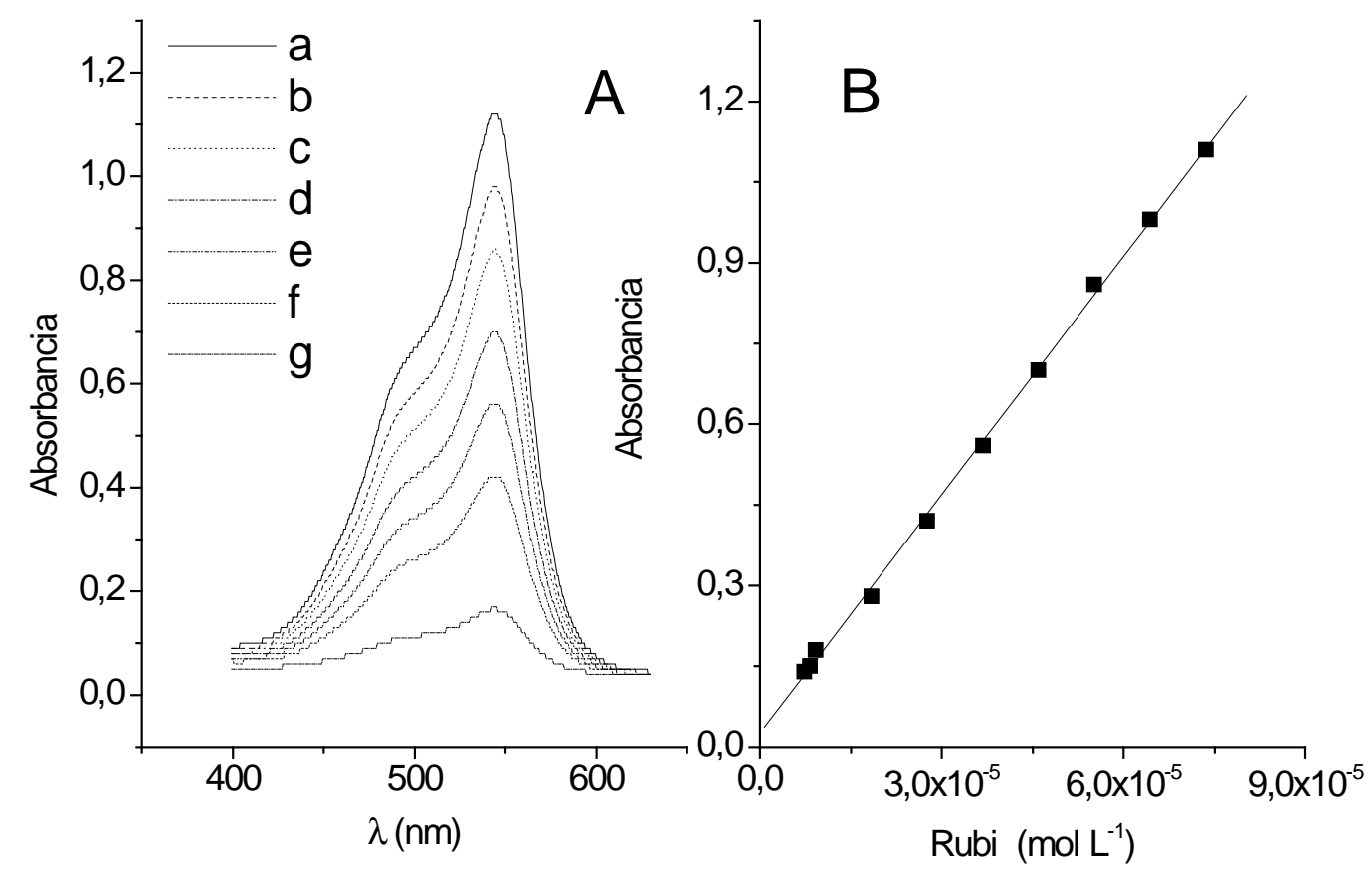

Figura 6 (A). Espectros de absorção UV-Vis para $P$ em tampão B-R pH 2,0. Curvas: (a)= 7,36; (b)= 6,44 (c) = 5,52; (d)= 4,60; (e)= 3,68; (f)= 2,76 e (g)= 1,84 (x10 $\left.0^{-5} \mathrm{~mol} \mathrm{~L}^{-1}\right)$. (B): Curva de calibração para P em tampão B-R pH 2,0.

A correlação entre a concentração de P e interpolados na equação da reta: $y=0,025$

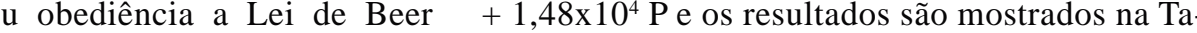
[44] em todo o intervalo investigado. A regressão bela 1.

linear entre essas grandezas permitiu a geração da função: $y=0,025+1,48 \times 10^{4} P, R=0,999, n=10$, onde $\mathrm{P}=$ a concentração do corante $\left(\mathrm{mol} \mathrm{L} \mathrm{L}^{-1}\right), \mathrm{R}=$ coeficiente de correlação e $\mathrm{n}=$ número de medicostes dados foi possível estimar 0 coeficiente de absortividade molar (e), para

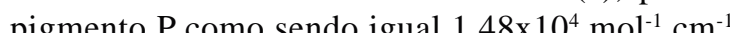
p. O limi $\mathrm{P}$ como sendo igual $1,48 \times 10^{-4} \mathrm{~mol}^{-1} \mathrm{~cm}^{-1}$ mol L ${ }^{-1}$, através de três leituras superior ao desvio-padrão do branco, dividido pela sensibilidade de calibração. A sensibilidade analítica foi calculada como sendo 2,07 X107 [45].

Aplicação do procedimento desenvolvido foi realizada através do método da curva de trabalho (Figura $6 \mathrm{~B}$ ). As amostras cedidas pelo CEFET-RN foram submetidas a diluição e efetuadas as leituras óticas. Os sinais de absorbância

$\mathrm{P}( \pm \mathrm{NC})\left(\mathrm{mol} \mathrm{L}^{-1}\right) *$

$9,0( \pm 0,5) \times 10^{-3}$

$1,0( \pm 0,6) \times 10^{-2}$

$9,6( \pm 0,3) \times 10^{-3}$

$9,8( \pm 0,4) \times 10^{-3}$

* NC= nível de confiança para 95\% para $\mathrm{n}=3$.

\section{Conclusões}

Os estudos espectrofotométricos mostraram que o corante P apresenta um valor bastante elevado de $\varepsilon$; enquanto a utilização da técnica potenciométrica possibilitou calcular seu pKa, comprovando a natureza fraca deste ácido orgânico. Além disso, o corante apresenta elevada sensibilidade analítica e de calibração, baixo limite de deteç̧ão e quantificação, e sua determinação em matrizes aquáticas pode ser realizada sem a necessidade de tratamentos enfadonhos das amostras.

Abstract: Pararosaniline dye (P) is a pigment which has a significant role in analysis of chemical substances and gram-positive and negative bacteria, as well as other microorganisms. Potentiometric essays of $\mathrm{P}$ have shown that the colorant is a weak monoprotic acid $(\mathrm{pKa}=8,78)$; and the spectrophotometry allows to estimate its molar absorption coefficient as $1,48 \times 10^{4}$ $\mathrm{mol}^{-1} \mathrm{~cm}^{-1} \mathrm{~L}$. The analytical curve for a determination of $\mathrm{P}$ has linearity between $7,36 \times 10^{-6}$ and $7,36 \times 10^{-5} \mathrm{~mol} \mathrm{~L}^{-1}$, and the methodology was application in biological samples.

Keywords: Determination, Ionization Constant, Molar Absorption Coefficient, Pararosaniline.

\section{Referências}

[1] R. K. Sani, U. C. Banerjee, Enzyme and Microbia Technology, 24 (1999) 433.

2] A. O. Martins, V. M. Canalli, C. M. N. Azevedo, M. Pires, Dyes and Pigments, 68 (2006) 227.

g. J. Jan, $\mathrm{H}_{\text {. Lin }} \mathrm{C}$ S. Lua, Journal of Photochemistry and Photobiology A: Chemistry, 184 (2006) 147.

[4] V. K. Gupta, A. Mittal, V. Gajbe, J. Mittal, Journal of Colloid and Interface Science, 319 (2008) 30.

5] D. R. Doerge, H. C. Chang R. L. Divi, M. I. Churchwell, Chem. Res. Toxicol. 11 (1998) 1098.

[6] Y. Eldem, I. Ozer, Dyes and Pigments, 60 (2004) 49.

[7] M. M. Kosanic, J. S. Trickovic, Journal of Photochemistry and Photobiology A: Chemistry, 149 (2002) 247.

[8] M. T. Ball, B. Morjaria, A. I. Motara, P. M. O’Boyle, E. J. Russell, J. K. Sugden, Dyes and Pigments, 36(3) (1998) 223.
[9] X. Feng, S. Zhu, H. Hou, Water SA, 32(1) (2006) 43. [10] V. Brezova, J. Pigosova, B. Havlinova, D. Dyoranova, M. Durovic, Dyes and Pigments, 61 (2004) 177.

[11] S. Y. An, S. K. Min, I. H. Cha, Y. L. Choi, Y. S. Cho, C. H. Kim, Y. C. Lee, Biotechnology Letters, 24 (2002) 1037. [12]

113] X. Li, G. Liu, J. Zhao, New J. Chem. 23 (1999) 1193. [14] S. Naskar, S. A. Pillay, M. Chanda, Journal of Photochemistry and Photobiology A: Chemistry, 113 (1998) 257.

[15] M. Kass, A. Ivaska, Analytica Chimica Acta, 449 (2001)

16] M. A. Segundo, A. O. S. S. Rangel, Analytica Chimica Acta, 427 (2001) 279.

A. A. Rangel, A. Cladera, V. Cerda, Analyst, 125 (2000) 1501. 
[18] H. Vekisquez, H. Ramfrez, J. Dfaz, M. G. Nava, B. S. Borrego, J. Morales, Journal of Chromatography A, 739 (1996) 295.

[19] K. Irgum, Anal. Chem. 57 (1985) 1335.

[20] S. K. Goyal, Environmental Monitoring and Assessment, 120 (2006) 461.

[21] M. Wahbi, H. Abdine, M. A. Koranyand M. H. AbdelHay, Analyst, 103 (1978) 876.

[22] M. C. Wu, C. M. Jiang, Y. Y. Ho, S. C. Shen, H. M. Chang, Food Chemistry, 100 (2007) 412.

[23] M. Achilli, L. Romele, Journal of Chromatography A, 847 (1999) 271.

[24] L. Romele, M. Achilli, Analyst, 123 (1998) 291.

[25] J. F. Goodwin, Clinical Chemistry, 17(6) (1971) 544.

[26] M. L. Singla, M. Singh, M. S. Walia, S. Singla, P.K. Mahapatra, Food Chemistry, 97 (2006) 737.

[27] B. Badri, Analyst, 113 (1988) 351.

[28] J. M. B. Sendra, S. Pescarolo, L. C. Rodríguez, A. M. G. Campaña, E. M. A. López, Fresenius J. Anal. Chem. 369 (2001) 715.

[29] L. G. Gracia, M. D. L. Castro, Analyst, 124 (1999) 1119. [30] W. J. Groah, J. Bradfleld; G. Gramp; R. Rudzinski; G. Herouxt, Environ. Sci. Technol. 25 (1991) 117.

[31] P. E. Georghiou, L. Harlick, L. Winsor, D. Snow, Anal. Chem, 55(3) (1983) 567.

[32] R. R. Mlksch, D. W. Anthon, L. Z. Fanning, C. D. Hollowell, K. Revzan, J. Glanvllle, Anal. Chem. 53 (1981) 2118.

[33] L. T. Gibsona, W. J. Kerra, A. Nordona, J. Reglinskia, C. Robertsona, L. Turnbulla, C. M. Watt, A. Cheungb, W. Johnstoneb, Analytica Chimica Acta, 623 (2008) 109.

[34] Q. Li, P. Sritharathikhum, M. Oshima, S. Motomizu, Analytica Chimica Acta, 612 (2008) 165.

[35] Y. Y. Maruo, J. Nakamura, M. Uchiyama, M. Higuchi, K. Izumi, Sensors and Actuators B, 129 (2008) 544.

[36] K. Shanthi, N. Balasubramanian; Microchemical Journal, 53 (1996) 168.

[37] K. Sonne, P. K. Dasgupta, Anal. Chem. 63 (1991) 427.

[38] A. Safavi, Z. Ramezani, Talanta, 44 (1997) 1225.

[39] S. K. Dangwal, S. Mithbavkar; Ann Occup. Hyg. 39(1) (1995) 115.

[40] E. Chirila, I. Carazeanu, S. Dobrinas, Talanta, 53 (2000) 271.

[41] P. P W. West, J. K. Carlton, Anal. Chem. 27 (1949) 1055. [42] P. W. West, E. S. Amls, Industrial and Engineering Chemistry, 18(6) (1946), 400.

[43] B. Zargar, H. Parham, A. Hatamie, Talanta, 77 (2009) 1328.

[44] D. C. Harris, Análise Química Quantitativa, LTC editora, Rio de Janeiro RJ, $5^{\mathrm{a}}$ edição, 2001.

[45] D. A. Skoog, D. M. West, F. J. Holler, S. R. Crouch, Fundamentos de Química Analítica, Ed. Cengage, São Paulo SP, 8ed, 2008. 